\title{
HER2/neu-directed therapy for biliary tract cancer
}

\author{
Milind Javle ${ }^{1 *}$, Chaitanya Churi ${ }^{1}$, HyunSeon C. Kang ${ }^{2}$, Rachna Shroff ${ }^{1}$, Filip Janku ${ }^{3}$, Rakesh Surapaneni ${ }^{4}$, \\ Mingxin Zuo ${ }^{1}$, Christian Barrera ${ }^{1}$, Humaid Alshamsi ${ }^{1}$, Sunil Krishnan', Lopa Mishra ${ }^{6}$, Robert A. Wolff', \\ Ahmed O. Kaseb ${ }^{1}$, Melanie B. Thomas ${ }^{7}$ and Abby B. Siege ${ }^{8^{*}}$
}

\begin{abstract}
Background: Biliary cancers are highly aggressive tumors that are often diagnosed an advanced disease stage and have a poor outcome with systemic therapy. Recent efforts towards molecular characterization have identified a subset of biliary patients that have HER2/neu amplification or mutation. HER2/neu amplification is associated with response to HER2/neu-directed therapy in breast and gastric cancers. However, the efficacy of HER2/neu-targeted therapy in biliary cancers is unknown.

Patients and methods: We retrospectively reviewed cases of advanced gallbladder cancer and cholangiocarcinoma with HER2/neu genetic aberrations or protein overexpression who received HER2/neu-directed therapy between 2007 and 2014. Clinical data were retrieved from medical records, and imaging studies were independently reviewed.

Results: Nine patients with gallbladder cancer and five patients with cholangiocarcinoma had received HER2/neudirected therapy (trastuzumab, lapatinib, or pertuzumab) during the study period. In the gallbladder cancer group, HER2/neu gene amplification or overexpression was detected in eight cases. These patients experienced disease stability $(n=3)$, partial response $(n=4)$, or complete response $(n=1)$ with HER2/neu-directed therapy. One patient had HER2/neu mutation and experienced a mixed response after lapatinib therapy. The duration of response varied from 8+ to 168 weeks (median 40 weeks), and three patients are still on therapy. One patient developed HER2/neu amplification as a secondary event after FGFR-directed therapy for FGF3-TACC3 gene fusion. The cholangiocarcinoma cases treated in this series had a higher proportion of HER2/neu mutations, and no radiological responses were seen in these patients despite HER2/neu-directed therapy.
\end{abstract}

Conclusions: HER2/neu blockade is a promising treatment strategy for gallbladder cancer patients with gene amplification and deserves further exploration in a multi-center study.

Keywords: Receptor, ErbB-2, Gallbladder neoplasms, Cancer of the biliary tract

\section{Introduction}

Gallbladder cancer is one of the most aggressive solid tumors and represents an important cause of cancerrelated mortality in South America and South Asia, while occurring less frequently in the United States and Western Europe. Late stage at presentation, early occurrence of liver and peritoneal metastases, and poor outcome with standard chemotherapy contribute to the poor

\footnotetext{
*Correspondence: mjavle@mdanderson.org; aas54@cumc.columbia.edu ${ }^{1}$ Department of Gastrointestinal (GI) Medical Oncology, Division of Cancer Medicine, The University of Texas MD Anderson Cancer Center, 1515 Holcombe Blvd. Unit Number 426, Room Number FC10.3062, Houston, TX 77030, USA

${ }^{8}$ Departments of Medicine and Surgery, Columbia University, 622 West 168th Street, PH-14, room 105 C, New York, NY 10032, USA

Full list of author information is available at the end of the article
}

prognosis of gallbladder cancer. Understanding the molecular characterization of this disease may help alter the dismal outcome with targeted therapeutics [1,2]. An estimated $12-15 \%$ of gallbladder cancers have HER2/neu amplification or protein overexpression using commonly accepted criteria for positivity [2-4]. Cholangiocarcinoma is increasing in incidence in the Western world. Recent efforts at molecular characterization have identified distinct subsets with prognostic and therapeutic implications [5]. HER2/neu mutation or amplification has also been reported in cholangiocarcinoma [6-8]. These patients may be candidates for HER2/neu-directed therapy.

The HER2/neu gene is located on the 17q12-q21 chromosomal region and acts as an oncogene in several

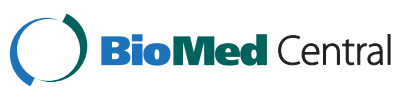


human cancers [9]. HER2/neu protein overexpression, either as the product of gene amplification or transcriptional deregulation, is observed in approximately $20 \%$ of breast and ovarian cancers and $12 \%$ of gastric cancers [10]. The overexpression and amplification of HER2/neu has also been demonstrated in gastricesophageal and endometrial cancer, and in these tumors, it is also usually associated with a worse prognosis [11-14]. The HER2/ neu receptors after dimerization can transactivate a number of downstream pathways like RAS-RAF-MEK-ERK1/ 2 or PI3k-AKT-mTOR resulting in cancer cell proliferation and cell survival $[15,16]$.

Several therapeutic agents have been developed for HER2/neu positive breast cancer: these include monoclonal antibodies such as trastuzumab and pertuzumab, small molecule tyrosine kinase inhibitors like lapatinib, and chemo-immunotherapy conjugates like ado-trastuzumab emtansine (T-DM1). These have substantially changed the management of breast and gastric cancers and have already been incorporated into standardized treatment algorithms [11, 17, 18]. However, data in regards to the efficacy of HER2/neu targeted therapy in biliary cancers are scarce.

\section{Patients and methods Case selection}

All patients selected had pathologically confirmed gallbladder or biliary adenocarcinoma, had received HER2/ neu-directed therapy, and had a minimum of 3 months of follow-up. Clinical, pharmacy, and pathology records were reviewed to identify cases that were HER2/neu positive and had received HER2-directed therapy. The study was approved by the Institutional Review Board of MD Anderson Cancer Center. Patient demographics, clinical data, survival data, and treatment history were retrieved from medical records.

\section{Tumor samples}

Paraffin embedded blocks were sectioned, and hematoxylin and eosin (H\&E) stained slides were reviewed by surgical pathology to confirm the tumor content in each section. Ten serial sections $(4 \mu \mathrm{m})$ were cut from selected tissue blocks and areas with tumor tissue were macrodissected from those slides using the H\&E slides as templates.

\section{DNA extraction}

The pathologic diagnosis of each case was confirmed on routine H\&E slides. All samples sent for DNA extraction contained a minimum of $20 \%$ DNA derived from tumor cells. DNA was extracted from $40 \mathrm{~mm}$ of fresh frozen, paraffin-embedded (FFPE) tissue using the Maxwell 16 FFPE Plus LEV DNA Purification kit (Promega
Corporation, Madison, WI, USA) and quantified using a standardized PicoGreen fluorescence assay (Invitrogen, Carlsbad, CA, USA).

\section{Next-generation sequencing (NGS)}

For subjects with adequate biopsy tissue, an amplicon library was generated from $10 \mathrm{ng}$ of DNA from each sample using the Ion Ampliseq Cancer Panel (Life Technologies, Carlsbad, CA, USA). FFPE cell pellets of the H2122 cell line diluted in the HL60 cell line were used as control. The 46 genes in the panel for detection of targetable mutations included the following: $A K T 1, B R A F$, FGFR1, GNAS, IDH1, FGFR2, KRAS, NRAS, PIK3CA, MET, RET, EGFR, JAK2, MPL, PDGFRA, PTEN, TP53, FGFR3, FLT3, KIT, ERBB2, ABL1, HNF1A, HRAS, ATM, RB1, CDH1, SMAD4, STK11, ALK, SRC, SMARCB1, VHL, MLH1, CTNNB1, KDR, FBXW7, APC, CSF1R, NPM1, SMO, ERBB4, CDKN2A, NOTCH1, JAK3, and PTPN11. Primers for PCR amplification included the 190-primer pair pool provided by the vendor with an additional primer pair that was custom added to cover the "hotspot" location on codon 17 of AKT1. Following PCR amplification of target sequences, barcodes were ligated to the amplicons using the Ion Xpress Barcode Adaptors Kit (Life Technologies, Carlsbad, CA, USA). Library quantification was then performed using the Bioanalyzer High Sensitivity DNA Chip (Agilent Technologies, Santa Clara, CA, USA). The library was diluted in nuclease-free water to obtain a final concentration of $16 \mathrm{pM}$. Emulsion PCR was performed manually using the Ion Xpress Template Kit (Life Technologies, Carlsbad, CA, USA) followed by manual breaking of the emulsion to isolate the ion spheres (ISPs). The quality of the DNA following PCR was measured using the Qubit IonSphere Quality control kit (Life Technologies, Carlsbad, CA, USA).

Selective ISPs with DNA were isolated and sequenced on an Ion 316 Chip (four samples/chip) or a Ion 318 Chip (eight samples/chip) using the vendor-provided sequencing kit (Life Technologies, Carlsbad, CA, USA). Successful sequencing of a sample required at least 300,000 reads with a quality score of AQ20 (1 misaligned base per 100 bases). For a wild-type call, a minimum coverage of $250 \times$ was required. As tumor specimens were admixed with normal tissue, a minimum coverage of $500 \times$ with at least $10 \%$ frequency was used as cutoff for a variant to be considered true. All variants detected by Ion PGM with at least $10 \%$ frequency were selected for confirmation by alternate platforms. Further details regarding the methodology and analysis have been described previously [19]. For four samples, NGS was performed by Foundation Medicine using the Illumina Hiseq 2000 Platform (Illumina, San Diego, CA, USA) for 236 targetable GAs; the methods have been described previously [20, 21]. 


\section{Immunohistochemistry for HER2/Neu}

Tissues were fixed in formalin and embedded in paraffin using standard techniques. The 4- $\mu$ m-thick histologic sections obtained from the TMAs were deparaffinized and hydrated in decreasing alcohol concentrations. Antigens were recovered by exposure to microwaves in citrate buffer ( $\mathrm{pH}$ 6.0) and washed in PBS ( $\mathrm{pH}$ 7.4). The monoclonal antibody anti-ErbB2 (NCL-CB11; Novocastra, Leica Biosystems, Wetzlar, Germany) was used at a dilution of 1:40. The primary antibody was incubated at room temperature for $60 \mathrm{~min}$ and then incubated with the complex Super Picture Polymer Detection Kit (Zymed Laboratories Inc., San Francisco, CA, USA) in a Dako autostainer (Dako, Glostrup, Denmark). Standard criteria for HER2/Neu scoring were used [3]. Fluorescent in situ hybridization (FISH) was performed using methods. Scoring was conducted according to the College of American Pathologists/American Society of Clinical Oncology (CAP/ ASCO) criteria for breast cancer [22].

\section{Results}

In the gallbladder cancer group, there were seven females and two males, with a median age of 63 years. One patient was Asian while others were Caucasian (Table 1). All had metastatic disease; seven received trastuzumab either alone $(n=2)$ or in combination with chemotherapy $(n=5)$. Other HER2-directed therapies were lapatinib and pertuzumab. One patient who received lapatinib had a mixed response; this patient had a HER2/neu mutation V777L. All other cases had HER2/neu amplification or overexpression. In all these cases, trastuzumab was associated with partial response $(n=4)$, stable disease $(n=3)$, or complete response $(n=1)$. (Figures 1 , 2,3 , and 4 illustrate the responses seen in this group). The duration of response varied from $8+$ to 168 weeks

Table 1 Patient characteristics

\begin{tabular}{lll}
\hline Characteristics & GBCA $(n=9)$ & CCA $(n=5)$ \\
\hline Sex & 2 & 5 \\
Male & 7 & 0 \\
Female & & \\
Age (years) & 0 & 2 \\
$20-39$ & 3 & 1 \\
$40-59$ & 6 & 2 \\
$\geq 60$ & & \\
Ethnicity & 1 & 0 \\
Asian & 8 & 5 \\
White & & 1 \\
Tumor differentiation & 1 & 4 \\
Poor & 8 & \\
Moderate & & \\
\hline
\end{tabular}

(median 40 weeks), and three patients are still on therapy. In two cases, therapy was administered neoadjuvantly for T4 disease and was followed by surgical resection. In one case, disease recurrence occurred 14 months after surgical resection, which was again successfully salvaged with trastuzumab (Fig. 1). Details regarding prior therapy administered, concurrent chemotherapy, and duration of treatment are described in Table 2.

One patient had FGF3-TACC3 fusion gene and had received prior therapy with the FGFR-directed agents pazopanib and dovitinib. Repeat biopsy after these therapies indicated that the tumor had developed HER2/neu amplification as a secondary event, while this was absent at initial diagnosis. This finding was confirmed by FISH analysis of the tumor biopsy before and after the FGFRdirected therapy. In this case, disease stability or response was noted after FGFR-directed therapy as well as from trastuzumab. This was also accompanied by a CA19-9 response (Fig. 5a-c).

In the cholangiocarcinoma group, the median age was 59 years; all patients were Caucasian with stage IV disease. Two patients had HER2/neu mutations (V777L and S310F) while the others had amplification using FISH or NGS (Table 3). Associated mutations noted on NGS along with response data are depicted in Table 4. All but one had received prior therapy, and two patients received no concurrent chemotherapy. In case of cholangiocarcinoma, no responses occurred from trastuzumab therapy, unlike the case with gallbladder cancer. In all cases, HER2/neu-directed therapies were well-tolerated without any notable cardiac events despite the length of therapy.

\section{Discussion}

HER2/neu gene is a key driver of tumorigenesis and its overexpression as a result of gene amplification is a critical target for therapy in breast cancer. Other solid tumors with reported overexpression of this gene include gastric adenocarcinoma (11\%), pulmonary adenocarcinoma (28\%), colorectal adenocarcinomas (17\%), pulmonary squamous (11\%), and pancreatic adenocarcinoma (7\%). There are several existing reports of HER $2 /$ neu overexpression in gallbladder cancer and the incidence has varied widely, depending upon the method used for assessment and scoring technique. Our group recently studied HER2/neu expression in 187 cases of gallbladder cancer; this is the largest reported series to date using the commonly accepted CAP/ASCO criteria. We noted than $13 \%$ of patients have HER2/neu overexpression (3+ by immunohistochemistry). Yoshikawa and colleagues reviewed 236 cases of surgically resected cholangiocarcinoma and reported a 0.9 and $8.5 \%$ incidence of HER2/ neu expression in intra- and extrahepatic cholangiocarcinoma, respectively. In their series, early stage disease 

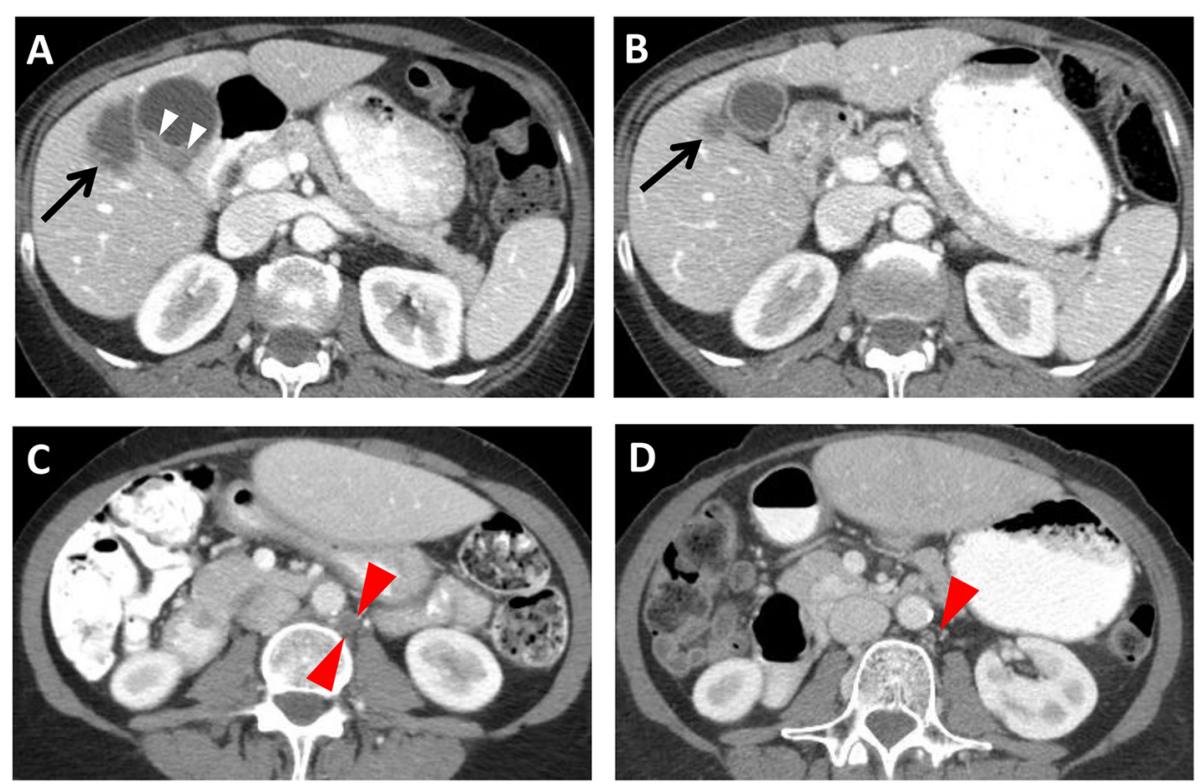

Fig. 1 A 61-year-old female with gallbladder carcinoma invading the liver. Axial contrast-enhanced CT images demonstrate a a $2.4 \times 1.3 \mathrm{~cm}$ polypoid mass (small arrowheads) in the gallbladder neck causing gallbladder obstruction. The mass directly invades the liver, with a $2.9 \times 3.9 \mathrm{~cm}$ liver mass (arrow). b After 3 months of trastuzumab and FOLFOX, the polypoid gallbladder mass is no longer visualized, and the liver mass decreased to $1.2 \times 1.1 \mathrm{~cm}$ (arrow). The patient was then treated with en bloc cholecystectomy and extended right hepatectomy, followed by capecitabine and trastuzumab for 7 months. c After 6 months of observation ( 14 months after surgery), the patient had small volume recurrence to retroperitoneal lymph nodes (large arrowheads). After treatment with FOXFOX and trastuzumab for 3 months, $\mathbf{d}$ a previously seen 1-cm retroperitoneal lymph node is nearly imperceptible
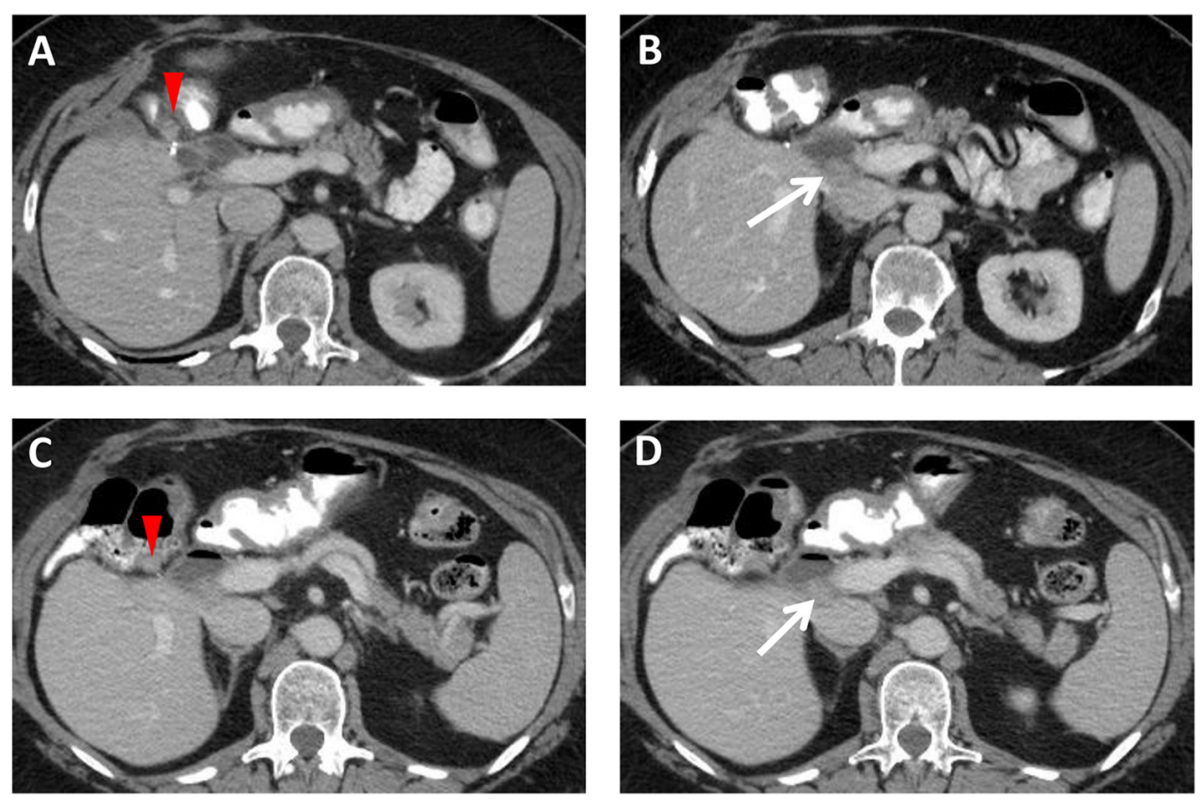

Fig. 2 A 64-year-old female with recurrent gallbladder carcinoma. Axial contrast-enhanced CT images demonstrate a a 1.2-cm nodule (arrowhead) in the gallbladder fossa adjacent to the hepatic flexure and $\mathbf{b}$ a $1.7-\mathrm{cm}$ nodule (arrow) in the portocaval region. Both nodules were new from the postoperative scan (following resection of recurrent tumor in the gallbladder fossa), in keeping with recurrence. $\mathbf{c}$, $\mathbf{d}$ Thirteen months later, both nodules are stable after treatment with trastuzumab 

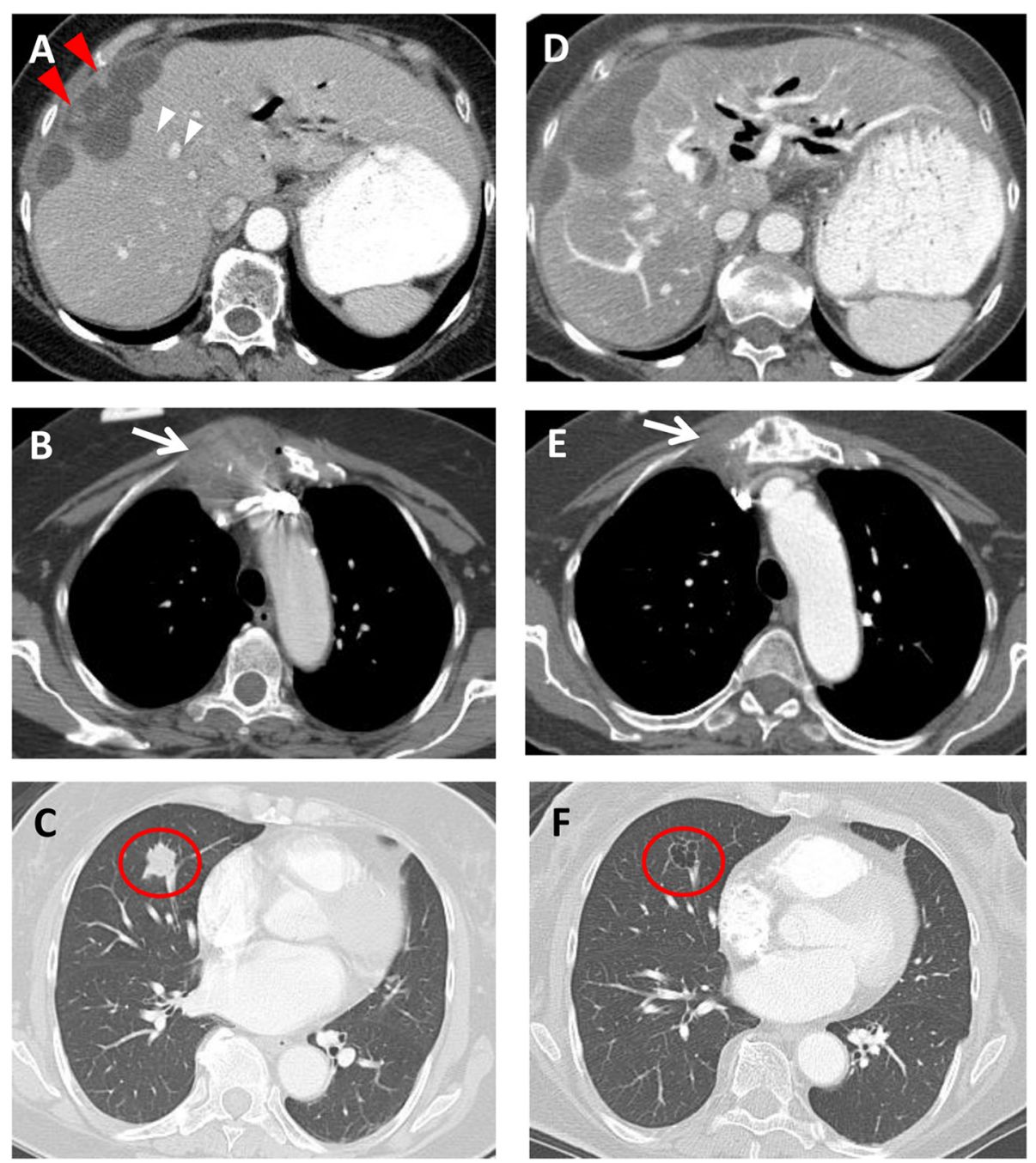

Fig. 3 A 62-year-old female with recurrent metastatic gallbladder carcinoma with carcinomatosis. Axial contrast-enhanced CT images demonstrate a enhancing perihepatic nodules (arrowheads), b a 4.8-cm metastasis destroying the sternum (arrow), and $\mathbf{c}$ a 1.8-cm lung metastasis (circle). After 3 months of trastuzumab, $\mathbf{d}$ the perihepatic nodules are no longer visualized. e The sternum has become sclerotic with decreased size of the metastasis (arrow), and $\mathbf{f}$ the lung metastasis has undergone cavitation (circle).

and well-differentiated tumors had a higher incidence of HER2/neu positivity. Data with regard to the prognostic value of HER2/neu overexpression in biliary cancers is mixed, with some studies suggesting a worse prognosis $[23,24]$, while others suggest the contrary $[25,26]$.

NGS for HER2/neu gene amplification may be regarded as the gold standard. However, this technology is dependent upon the quality of the pathological sample and DNA degradation may result from formalin fixation. In our retrospective series, the criteria for HER2/neu positivity were stringent and included $3+$ protein expression on immunohistochemistry, FISH ratio higher than 2.2 or HER2/neu genetic aberration in a Clinical Laboratory Improvement Amendment (CLIA) compliant laboratory. Slamon and others have described the remarkable success of HER2/neu-targeted therapy for breast cancer
[27-29]. In gastric cancer, the trastuzumab for gastric adenocarcinoma (ToGA) trial established the benefit of trastuzumab in combination with a fluoropyrimidine plus cisplatin in a randomized phase 3 trial of gastric cancer patients with overexpression or gene amplification of HER2/neu [30]. It is logical therefore to investigate HER2/ neu targeting in other cancers that have gene amplification or overexpression.

Although the number of cases in this retrospective review is limited, to our knowledge, this is the largest reported case series of gallbladder cancer with HER2/ neu amplification or overexpression treated with targeted therapy. Our experience demonstrates that HER2/ neu-directed therapy appears to be beneficial for gallbladder cancer cases with HER2/neu amplification. Only one case in our series failed to respond, this tumor had 

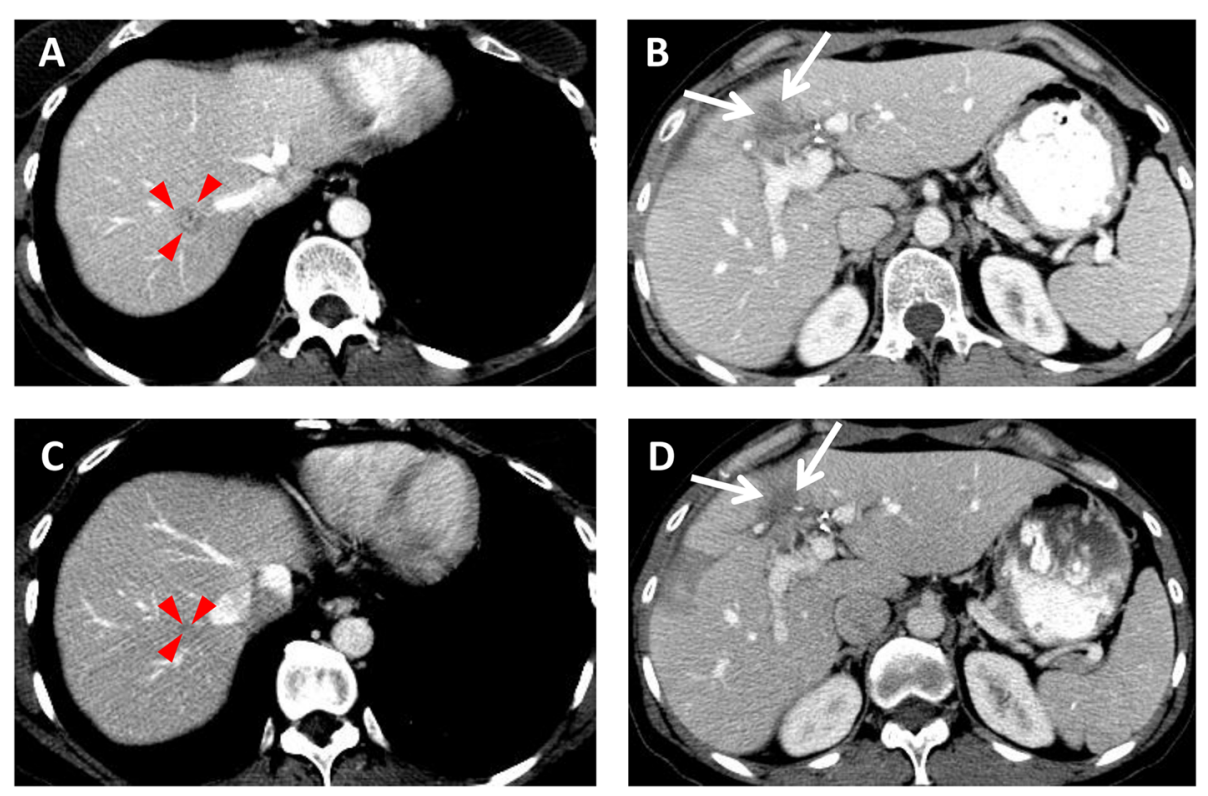

Fig. 4 A 45-year-old female with metastatic gallbladder carcinoma. Axial contrast-enhanced CT images demonstrate a a 1.5-cm liver metastasis (arrowheads) and $\mathbf{b}$ prominent soft tissue (arrows) in the cholecystectomy bed abutting the liver. After 2 months of treatment with trastuzumab, c the liver metastasis is barely visible at $4 \mathrm{~mm}$, and $\mathbf{d}$ the soft tissue mass in the resection bed, representing recurrent tumor, is decreased. She was stable for an additional 5 months, then had recurrence in the resection bed

HER2/neu mutation (V777L in the kinase domain). Two prior case reports have described responses with trastuzumab in subjects with gallbladder cancer. In the first, a 45-year-old woman received paclitaxel and trastuzumab and a dramatic regression of her lung metastases occurred [31]. In the second, a 61-year-old woman also with gallbladder cancer had a remarkable response to weekly paclitaxel and trastuzumab, which persisted when trastuzumab was continued as a single agent [32]. An estimated 80-100,000 cases of gallbladder cancer are

Table 2 Gallbladder cancer: prior therapy, concurrent chemotherapy, and treatment duration

\begin{tabular}{|c|c|c|c|c|c|c|c|c|}
\hline Pt \# & Sites of disease & Prior therapy & $\begin{array}{l}\text { HER2/neu } \\
\text { test }\end{array}$ & $\begin{array}{l}\text { HER2/neu } \\
\text { therapy }\end{array}$ & $\begin{array}{l}\text { Concurrent } \\
\text { therapy }\end{array}$ & $\begin{array}{l}\text { Duration of } \\
\text { therapy (weeks) }\end{array}$ & $\begin{array}{l}\text { Overall survival } \\
\text { (weeks) }\end{array}$ & $\begin{array}{l}\text { Best } \\
\text { response }\end{array}$ \\
\hline 1 & Bone, liver & $\mathrm{Nil}$ & IHC 3+ & Trastuzumab & $\begin{array}{l}\text { Gemcitabine, } \\
\text { cisplatin }\end{array}$ & 7 & 20 & SD \\
\hline 2 & $\begin{array}{l}\text { Peritoneum, } \\
\text { lung, liver }\end{array}$ & $\begin{array}{l}\text { Gemcitabine + cisplatin, } \\
\text { FOLFIRI + erbitux }\end{array}$ & $\begin{array}{l}\text { Mutation (NGS) } \\
\text { V777/L }\end{array}$ & Lapatinib & Sirolimus & 15 & 19 & MR \\
\hline 3 & $\begin{array}{l}\text { Retroperitoneal } \\
\text { LN, liver }\end{array}$ & Nil & $\begin{array}{l}\text { FISH } \\
\text { amplification }\end{array}$ & Trastuzumab & Nil & 38 & 113 & $C R$ \\
\hline 4 & Liver & $\begin{array}{l}\text { Gemcitabine + cisplatin, } \\
\text { capecitabine, FOLFOX }\end{array}$ & $\begin{array}{l}\text { ERBB2 NGS } \\
\text { amplification }\end{array}$ & Trastuzumab & $\begin{array}{l}\text { Gemcitabine + } \\
\text { irinotecan }\end{array}$ & 40 & 62 & PR \\
\hline 5 & Liver, LN & Gemcitabine + cisplatin & $\begin{array}{l}\text { ERBB2 NGS } \\
\text { amplification }\end{array}$ & Trastuzumab & $\begin{array}{l}\text { FOLFOX } \\
\text { capecitabine }\end{array}$ & 92 & 92 & PR \\
\hline 6 & $\begin{array}{l}\text { Sternum, } \\
\text { pleura, lung }\end{array}$ & Gemcitabine, capecitabine & $\begin{array}{l}\text { AMPLIFIED } \\
\text { (FISH) }\end{array}$ & Trastuzumab & & 168 & 178 & PR \\
\hline 7 & $\begin{array}{l}\text { Retroperitoneal } \\
\text { LN, } \\
\text { celiac LN }\end{array}$ & Nil & $\begin{array}{l}\text { AMPLIFIED } \\
\text { (FISH) }\end{array}$ & Trastuzumab & $\begin{array}{l}\text { Gemcitabine + } \\
\text { cisplatin }\end{array}$ & $22+$ & $22+$ & PR \\
\hline 8 & $\begin{array}{l}\text { Retroperitoneal LN, } \\
\text { supraclavicular LN }\end{array}$ & $\begin{array}{l}\text { Gemcitabine + capecitabine, } \\
\text { gemcitabine + cisplatin, } \\
\text { pazopanib, dovitinib }\end{array}$ & $\begin{array}{l}\text { ERBB2 NGS } \\
\text { amplification }\end{array}$ & $\begin{array}{l}\text { Trastuzumab + } \\
\text { pertuzumab }\end{array}$ & Nil & $8+$ & $8+$ & SD \\
\hline 9 & Lungs, brain & $\begin{array}{l}\text { Gemcitabine + cisplatin } \\
\text { radiation }\end{array}$ & IHC 3+ & Trastuzumab & $\begin{array}{l}\text { Paclitaxel } \\
\text { capecitabine }\end{array}$ & 72 & $96+$ & PR \\
\hline
\end{tabular}

HER2-positive tumors IHC 3+, FISH HER2/centromere 17 ratio $\geq 2.0$ or both

$S D$ stable disease, $M R$ mixed response, $P R$ partial response 

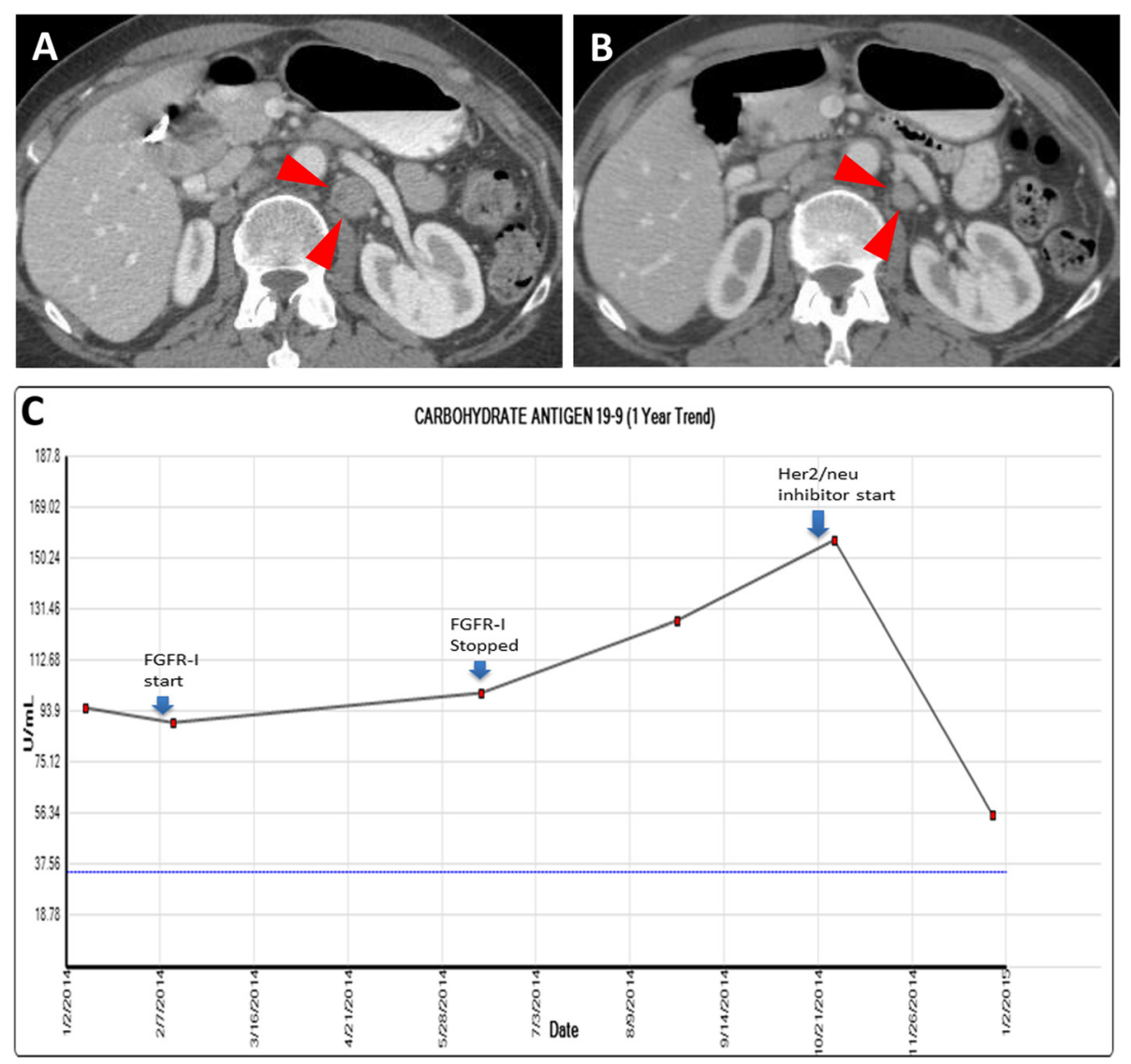

Fig. 5 A 73-year-old female with metastatic retroperitoneal lymphadenopathy from gallbladder carcinoma. Axial contrast-enhanced CT images demonstrate $\mathbf{a}$ a $1.9-\mathrm{cm}$ lymph node (arrowheads) posterior to the left renal vein. After 2 months of trastuzumab and pertuzumab, $\mathbf{b}$ the lymph node decreased to $1.2 \mathrm{~cm}$. c Her CA 19-9 response to HER2/neu inhibition after prior FGFR inhibitor therapy

diagnosed worldwide annually, and the benefit of targeted therapy for those with $H E R 2 / n e u$ amplification would be substantial.

In this review, we also report a patient with gallbladder cancer with FGF3-TACC3 fusion gene with negative HER2/neu gene amplification on NGS (confirmed by IHC and FISH, both being negative) who was treated with targeted FGFR inhibitors (dovitinib followed by pazopanib) resulting in initial response. She underwent repeat tumor biopsy on disease progression that then showed HER2/neu amplification on NGS (confirmed by IHC and FISH). In this case, we hypothesize that the HER $2 /$ neu amplification was a secondary event leading to resistance to FGFR inhibitors. Interestingly, FGFR2 addiction has been reported to be a mechanism leading to lapatinib resistance in breast cancer [33]. However, to our knowledge this is the first report of HER2/neu amplification as a mechanism of resistance to FGFR inhibitors. This finding

Table 3 Cholangiocarcinoma: prior therapy, concurrent chemotherapy, and treatment duration

\begin{tabular}{|c|c|c|c|c|c|c|c|c|}
\hline Pt \# & Sites of disease & Prior therapy & HER2/neu test & $\begin{array}{l}\text { HER2/neu } \\
\text { therapy }\end{array}$ & Concurrent therapy & $\begin{array}{l}\text { Duration } \\
\text { of therapy }\end{array}$ & $\begin{array}{l}\text { Overall } \\
\text { survival }\end{array}$ & $\begin{array}{l}\text { Best } \\
\text { response }\end{array}$ \\
\hline 1 & $\begin{array}{l}\text { Liver, mediastinum, } \\
\text { Lung }\end{array}$ & Gemcitabine folfirinox & $\begin{array}{l}\text { Mutation (NGS) } \\
\text { V777L }\end{array}$ & Trastuzumab & Gemcitabine, docetaxel & 19 & 29 & PD \\
\hline 2 & Liver, peritoneum, lung & Gemcitabine + cisplatin & ERBB2 amp NGS & Trastuzumab & FOLFOX & 14 & 25 & PD \\
\hline 3 & Mediastinum & $\begin{array}{l}\text { Gemcitabine + cisplatin, } \\
\text { FOLFIRI, GTX }\end{array}$ & ERBB2 NGS S310F & Trastuzumab & FOLFOX & 7 & 7 & PD \\
\hline 4 & Liver, lung & Nil & AMPLIFIED (FISH) & Trastuzumab & & 6 & 8 & PD \\
\hline 5 & Lung, liver, bones & Gemcitabine + cisplatin & AMPLIFIED (FISH) & Trastuzumab & & 10 & 12 & PD \\
\hline
\end{tabular}

HER2-positive tumors (IHC 3+, FISH HER2/centromere 17 ratio $\geq 2.0$ or both

$S D$ stable disease, $P D$ progressive disease, $C R$ complete response, $P R$ partial response 
Table 4 Associated mutations noted on NGS along with response data

\begin{tabular}{|c|c|c|c|c|c|c|}
\hline Cancer type & HER2/neu status & Associated mutations & $\begin{array}{l}\text { Best } \\
\text { response }\end{array}$ & Agent & $\begin{array}{l}\text { PFS } \\
\text { (weeks) }\end{array}$ & $\begin{array}{l}\text { OS } \\
\text { (weeks) }\end{array}$ \\
\hline Cholangioca & Mutation (V777L) & FGFR3, TP53 & SD & Trastuzumab & 19 & 29 \\
\hline Cholangioca & Amplification & BAP1, CDKN2A, KDM6A, PBRM1, SETD2 & PD & Trastuzumab & 14 & 25 \\
\hline Cholangioca & Mutation (S310F) & KRAS, MYC, TP53, EZH2, MSH6 & PD & Trastuzumab & 7 & 7 \\
\hline Cholangioca & Amplification & & PD & Trastuzumab & 6 & 8 \\
\hline Cholangioca & Amplification & & PD & Trastuzumab & 10 & 12 \\
\hline Gallbladder cancer & Amplification & PIK3CA, CDKN2A/B, TP53, ZNF703 & MR & Lapatinib & 15 & 19 \\
\hline Gallbladder cancer & Amplification & TP53 & PR & Trastuzumab & $>92$ & $>92$ \\
\hline Gallbladder cancer & Amplification & NRAS, PIK3CA, RB1,PTEN, TP53 & PR & Trastuzumab & $>40$ & $>62$ \\
\hline Gallbladder cancer & Amplification & & PR & Trastuzumab & 168 & 178 \\
\hline Gallbladder cancer & Amplification & & PR & Trastuzumab & 38 & 113 \\
\hline Gallbladder cancer & Amplification & FGFR3-TACC3 fusion, TP53, CCNE1, MCL1, MYC & SD & Trastuzumab + pertuzumab & +8 & +8 \\
\hline
\end{tabular}

$S D$ stable disease, $P D$ progressive disease, $M R$ mixed response, $P R$ partial response

supports the role of repeat tumor biopsy in the case of disease progression for re-assessment of HER2/neu status in select cases.

In contrast, trastuzumab was less effective in the case of cholangiocarcinoma and there were no responses noted in our series. Two of these cases with cholangiocarcinoma had HER2/neu mutations, which are not known to be responsive to trastuzumab, but may potentially respond to tyrosine kinase inhibitors like lapatinib, neratinib, and canertinib [34]. HER2/neu-targeted therapy has also not proven to be effective despite the presence of gene amplification in diseases like colon and pancreas cancers. The reason for this lack of efficacy is not known. Junttila et al. demonstrated that trastuzumab disrupts ligand-independent ErbB2/ErbB3/PI3K complexes blocking AKT signaling; when $P I 3 K$ is mutated or dysfunctional, complex disruption does not inhibit $A K T$ [35]. Another possible explanation could involve the higher rate of KRAS mutations seen in intrahepatic cholangiocarcinomas as compared with gallbladder cancers, possibly mediating resistance to upstream HER2 blockade $[2,5,36]$.

In summary, HER2/neu-directed therapy is a promising avenue for patients with gallbladder cancer with gene amplification and should be further explored in an international clinical trial.

\section{Competing interests}

The authors declare that they have no competing interests.

\section{Authors' contributions}

MJ, AS, CC, HK, and CB made substantial contributions to the conception and design, acquisition, analysis, and interpretation of data. MJ, MZ, and AS are responsible for the revision, final approval, and drafting the article or revising it critically for important intellectual content. RS, FP, RSu, HA, SK, RW, $A K$, and $M B$ helped in the acquisition, analysis, and interpretation of data. All authors read and approved the final manuscript.

\section{Acknowledgements}

This study was supported by Elaine Sis Murphy Cholangiocarcinoma Fund and Lee and Graeme Dayton Fund.

\section{Author details}

${ }^{1}$ Department of Gastrointestinal (GI) Medical Oncology, Division of Cancer Medicine, The University of Texas MD Anderson Cancer Center, 1515 Holcombe Blvd. Unit Number 426, Room Number FC10.3062, Houston, TX 77030, USA. ${ }^{2}$ Department of Diagnostic Radiology, Division of Diagnostic Imaging, The University of Texas MD Anderson Cancer Center, Houston, TX, USA. ${ }^{3}$ Department of Investigational Cancer Therapeutics, Division of Cancer Medicine, The University of Texas MD Anderson Cancer Center, Houston, TX, USA. ${ }^{4}$ Scott \& White Clinic, Temple, TX, USA. ${ }^{5}$ Department of Radiation Oncology, Division of Radiation Oncology, The University of Texas MD Anderson Cancer Center, Houston, TX, USA. ${ }^{6}$ Department of Gastroenterology, The University of Texas MD Anderson Cancer Center, Houston, TX, USA. ${ }^{7}$ Gibbs Cancer Center \& Research Institute, Spartanburg, SC, USA. ${ }^{8}$ Departments of Medicine and Surgery, Columbia University, 622 West 168th Street, PH-14, room 105 C, New York, NY 10032, USA.

Received: 19 March 2015 Accepted: 12 May 2015

Published online: 29 May 2015

\section{References}

1. Li M, Zhang Z, Li X, Ye J, Wu X, Tan Z, et al. Whole-exome and targeted gene sequencing of gallbladder carcinoma identifies recurrent mutations in the ErbB pathway. Nat Genet. 2014;46(8):872-6.

2. Javle M, Rashid A, Churi C, Kar S, Zuo M, Eterovic AK, et al. Molecular characterization of gallbladder cancer using somatic mutation profiling. Hum Pathol. 2014;45(4):701-8.

3. Wolff AC, Hammond ME, Hicks DG, Dowsett M, McShane LM, Allison KH, et al. Recommendations for human epidermal growth factor receptor 2 testing in breast cancer: American Society of Clinical Oncology/College of American Pathologists clinical practice guideline update. American Society of Clinical Oncology; College of American Pathologists. J Clin Oncol. 2013;31(31):3997-4013.

4. Roa I, de Toro G, Schalper K, de Aretxabala X, Churi C, Javle M. Overexpression of the HER2/neu gene: a new therapeutic possibility for patients with advanced gallbladder cancer. Gastrointestinal Cancer Res. 2014;7(2):42-8.

5. Churi CR, Shroff R, Wang Y, Rashid A, Kang HC, Weatherly J, et al. Mutation profiling in cholangiocarcinoma: prognostic and therapeutic implications. PLoS One. 2014;9(12), e115383.

6. Kim HJ, Yoo TW, Park DI, Park JH, Cho YK, Sohn Cl, et al. Gene amplification and protein overexpression of HER-2/neu in human extrahepatic cholangiocarcinoma as detected by chromogenic in situ hybridization and 
immunohistochemistry: its prognostic implication in node-positive patients. Ann Oncol. 2007;18(5):892-7.

7. Radaeva S, Ferreira-Gonzalez A, Sirica AE. Overexpression of C-NEU and C-MET during rat liver cholangiocarcinogenesis: a link between biliary intestinal metaplasia and mucin-producing cholangiocarcinoma. Hepatology. 1999;29(5):1453-62.

8. Ukita Y, Kato M, Terada T. Gene amplification and mRNA and protein overexpression of c-erbB-2 (HER-2/neu) in human intrahepatic cholangiocarcinoma as detected by fluorescence in situ hybridization, in situ hybridization, and immunohistochemistry. J Hepatol. 2002;36(6):780-5.

9. Gutierrez C, Schiff R. HER2: biology, detection, and clinical implications. Arch Pathol Lab Med. 2011;135(1):55-62.

10. Yang XR, Chang-Claude J, Goode EL, Couch FJ, Nevanlinna H, Milne RL, et al. Associations of breast cancer risk factors with tumor subtypes: a pooled analysis from the Breast Cancer Association Consortium studies. J Natl Cancer Inst. 2011;103(3):250-63.

11. Chua TC, Merrett ND. Clinicopathologic factors associated with HER2positive gastric cancer and its impact on survival outcomes-a systematic review. Int J Cancer J Int Du Cancer. 2012;130(12):2845-56.

12. English DP, Roque DM, Santin AD. HER2 expression beyond breast cancer: therapeutic implications for gynecologic malignancies. Mol Diag Ther. 2013;17(2):85-99

13. Penault-Llorca F, Chenard MP, Bouche O, Emile JF, Bibeau F, Metges JP, et al. HER2 and gastric cancer. Recommendations for clinical practice in 2011. Ann Pathol. 2011;31(2):78-87.

14. Boku N. HER2-positive gastric cancer. Gastric Cancer. 2014;17:1-12.

15. Wang Y, Liu Y, Du Y, Yin W, Lu J. The predictive role of phosphatase and tensin homolog (PTEN) loss, phosphoinositol-3 (PI3) kinase (PIK3CA) mutation, and PI3K pathway activation in sensitivity to trastuzumab in HER2positive breast cancer: a meta-analysis. Curr Med Res Opin. 2013;29(6):633-42.

16. Segatto O, Pelicci G, Giuli S, Digiesi G, Di Fiore PP, McGlade J, et al. Shc products are substrates of erbB-2 kinase. Oncogene. 1993;8(8):2105-12.

17. Wong H, Yau T. Targeted therapy in the management of advanced gastric cancer: are we making progress in the era of personalized medicine? Oncologist. 2012;17(3):346-58.

18. Terashima M, Kitada K, Ochiai A, Ichikawa W, Kurahashi I, Sakuramoto S, et al. Impact of expression of human epidermal growth factor receptors EGFR and ERBB2 on survival in stage II/III gastric cancer. Clin Cancer Res. 2012;18(21):5992-6000.

19. Kanagal-Shamanna R, Portier BP, Singh RR, Routbort MJ, Aldape KD, Handal $B A$, et al. Next-generation sequencing-based multi-gene mutation profiling of solid tumors using fine needle aspiration samples: promises and challenges for routine clinical diagnostics. Modern Pathol. 2014;27(2):314-27.

20. Ross JS, Cronin M. Whole cancer genome sequencing by next-generation methods. Am J Clin Pathol. 2011;136(4):527-39.

21. Gnirke A, Melnikov A, Maguire J, Rogov P, LeProust EM, Brockman W, et al. Solution hybrid selection with ultra-long oligonucleotides for massively parallel targeted sequencing. Nat Biotechnol. 2009;27(2):182-9.

22. Middleton LP, Price KM, Puig P, Heydon LJ, Tarco E, Sneige N, et al. Implementation of American Society of Clinical Oncology/College of American Pathologists HER2 guideline recommendations in a tertiary care facility increases HER2 immunohistochemistry and fluorescence in situ hybridization concordance and decreases the number of inconclusive cases. Arch Pathol Lab Med. 2009;133(5):775-80.

23. Settakorn J, Kaewpila N, Burns GF, Leong AS. FAT, E-cadherin, beta catenin, HER 2/neu, Ki67 immuno-expression, and histological grade in intrahepatic cholangiocarcinoma. J Clin Pathol. 2005:58(12):1249-54.

24. Nakazawa K, Dobashi Y, Suzuki S, Fujii H, Takeda Y, Ooi A. Amplification and overexpression of c-erbB-2, epidermal growth factor receptor, and c-met in biliary tract cancers. J Pathol. 2005;206(3):356-65.

25. Yoshikawa D, Ojima H, Iwasaki M, Hiraoka N, Kosuge T, Kasai S, et al. Clinicopathological and prognostic significance of EGFR, VEGF, and HER2 expression in cholangiocarcinoma. Br J Cancer. 2008;98(2):418-25.

26. Shafizadeh N, Grenert JP, Sahai V, Kakar S. Epidermal growth factor receptor and HER-2/neu status by immunohistochemistry and fluorescence in situ hybridization in adenocarcinomas of the biliary tree and gallbladder. Hum Pathol. 2010;41(4):485-92

27. Slamon DJ, Leyland-Jones B, Shak S, Fuchs H, Paton V, Bajamonde A, et al. Use of chemotherapy plus a monoclonal antibody against HER2 for metastatic breast cancer that overexpresses HER2. N Engl J Med. 2001;344(11):783-92.
28. Baselga J, Cortes J, Kim SB, Im SA, Hegg R, Im YH, et al. Pertuzumab plus trastuzumab plus docetaxel for metastatic breast cancer. N Engl J Med. 2012;366(2):109-19.

29. Verma S, Miles D, Gianni L, Krop IE, Welslau M, Baselga J, et al. Trastuzumab emtansine for HER2-positive advanced breast cancer. N Engl J Med. 2012;367(19):1783-91.

30. Bang YJ, Van Cutsem E, Feyereislova A, Chung HC, Shen L, Sawaki A, et al. Trastuzumab in combination with chemotherapy versus chemotherapy alone for treatment of HER2-positive advanced gastric or gastrooesophageal junction cancer (ToGA): a phase 3, open-label, randomised controlled trial. Lancet. 2010;376(9742):687-97.

31. Law LY. Dramatic response to trastuzumab and paclitaxel in a patient with human epidermal growth factor receptor 2-positive metastatic cholangiocarcinoma. J Clin Oncol. 2012;30(27):e271-3.

32. Sorscher $\mathrm{S}$. Marked radiographic response of a HER-2-overexpressing biliary cancer to trastuzumab. Cancer Manag Res. 2014;6:1-3.

33. Azuma K, Tsurutani J, Sakai K, Kaneda H, Fujisaka Y, Takeda M, et al. Switching addictions between HER2 and FGFR2 in HER2-positive breast tumor cells: FGFR2 as a potential target for salvage after lapatinib failure. Biochem Biophys Res Commun. 2011;407(1):219-24.

34. Bose R, Kavuri SM, Searleman AC, Shen W, Shen D, Koboldt DC, et al. Activating HER2 mutations in HER2 gene amplification negative breast cancer. Cancer Discov. 2013;3(2):224-37.

35. Junttila TT, Akita RW, Parsons K, Fields C, Lewis Phillips GD, Friedman LS, et al. Ligand-independent HER2/HER3/PI3K complex is disrupted by trastuzumab and is effectively inhibited by the PI3K inhibitor GDC-0941. Cancer Cell. 2009;15(5):429-40.

36. Deshpande V, Nduaguba A, Zimmerman SM, Kehoe SM, Macconaill LE, Lauwers GY, et al. Mutational profiling reveals PIK3CA mutations in gallbladder carcinoma. BMC Cancer. 2011;11:60.

\section{Submit your next manuscript to BioMed Central and take full advantage of:}

- Convenient online submission

- Thorough peer review

- No space constraints or color figure charges

- Immediate publication on acceptance

- Inclusion in PubMed, CAS, Scopus and Google Scholar

- Research which is freely available for redistribution 